\title{
EL GOBIERNO ABIERTO: ¿UNA “TERCERA GENERACIÓN” DE REFORMAS DEL ESTADO?
}

\author{
THE OPEN GOVERNMENT: ¿A "THIRD GENERATION" OF STATE REFORMS?
}

Carlos Miguel Rodrigues de Caires ${ }^{1}$

Sayda Marlene Unkuch Saant ${ }^{2}$

\section{Resumen}

En torno al concepto de gobierno abierto se ha suscitado un reciente pero muy amplio debate político y académico. Un eje que permite articular este entramado normativo y analítico es el de las reformas del Estado. En este trabajo se argumenta que en torno a la noción de gobierno abierto y, más apropiadamente, al menos en el mundo latino, a la de Estado abierto, se ha configurado un nuevo paradigma normativo, estratégico y operativo de reforma estatal que apunta a la conformación de una matriz socio-céntrica, basada en los principios de apertura, participación y colaboración.

\section{Palabras clave}

Reforma del Estado, gobierno abierto, Estado abierto, transparencia, participación.

\section{Abstract}

A recent but very broad political and academic debate has arisen around the concept of open government. The discussion about State reforms can articulate this normative and analytical framework. In this paper, it is argued that around the notion of open government and, more appropriately, at least in the Latin world, the notion of open State, has emerged a new normative, strategic and operative paradigm of State reform, oriented toward the conformation of a socio-centric matrix, based on the principles of openness, participation and collaboration.

\section{Keywords}

State reform, open government, open state, transparency, participation.

\footnotetext{
${ }^{1}$ Facultad Latinoamericana de Ciencias Sociales (FLACSO-Ecuador). Departamento de Asuntos Públicos. Correo electrónico: cmrodriguesdefl@flacso.edu.ec.

${ }^{2}$ Ministerio de Educación del Ecuador - Coordinación Zonal 7. Correo electrónico: saydaunkuch@gmail.com.
} 


\section{Introducción}

La crisis del Estado ha revoloteado en la agenda política y académica al menos desde inicios del siglo XX (Cassese, 2003). Sin embargo, tras la publicación a mediados de la década de 1970 del conocido informe de la Comisión Trilateral sobre las crisis de «gobernabilidad» de las democracias (Crozier, Huntington y Watanuki, 1975), el debate sobre el carácter problemático del Estado adquirió una centralidad inédita. Desde entonces, han sido concebidas e implementadas varias "generaciones" u "oleadas» de reformas estatales, guiadas por marcos normativos, categorías conceptuales y lógicas de intervención heterogéneas.

El denominado "gobierno abierto» (open government, en inglés) ha irrumpido como la propuesta más reciente de transformación de la gobernanza de los asuntos públicos. Su rápido ascenso se ha beneficiado de su aparente «adecuación» a las necesidades y oportunidades del contexto actual, marcado por una triple crisis de legitimidad, confianza y eficacia de los sistemas políticoadministrativos. Sin embargo, en parte por su propia novedad y en parte por su superposición con otros conceptos y nociones, la de gobierno abierto sigue siendo una categoría difusa, de contenidos disputados, fronteras borrosas e implicaciones imprecisas.

A partir de los interrogantes ¿constituye el gobierno abierto una propuesta de reforma del Estado?; y si es así, ¿es posible considerarlo el paradigma ordenador de una «tercera» ola de reformas estatales? Se argumenta que en torno a esta categoría -y más apropiadamente, al menos en el mundo latino, a la de Estado abierto- se configura el marco normativo, estratégico y operativo de una «tercera generación» de reformas, distinguible por sus principios, métodos y técnicas de las propuestas precedentes.

El documento está organizado en cinco secciones. Las primeras tres partes contienen una revisión teórica acotada y parcial de los tres principales ejes conceptuales identificados: Estado, reforma del Estado y gobierno abierto. En la cuarta sección se plantean los alcances e implicaciones del gobierno abierto como proyecto de reforma estatal, justificando el uso de la noción, aún más reciente, de Estado abierto. Finalmente, en la última parte se vierten algunas reflexiones sobre los dilemas y desafíos abiertos por este paradigma emergente.

\section{El Estado como institución: dominación, poder y autonomía}

El Estado no puede ser comprendido en tanto problema teórico, sin remitirse previamente a nociones más generales que lo configuran y le dan sentido. El poder constituye la esencia de lo político, de modo que «si la teoría del Estado puede ser considerada como una parte de la teoría política, la teoría política a su vez puede ser considerada como una parte de la teoría del poder» (Bobbio, 2006, p. 103).

Para Weber, la dominación, en tanto caso especial de poder, está determinada por relaciones «autoritativas» de mando y obediencia. La relación entre dominación y gobierno es estrecha: toda dominación funciona en forma de gobierno y todo gobierno funda su eficacia en algún grado de dominación (Weber, 2004, p. 696). El Estado no es más que una forma histórica de dominación; el modo de dominación propio de la modernidad.

La realidad material y la realidad semántica del Estado emergieron casi simultáneamente, producto de «una evolución lenta y de un proceso continuo que ha tendido a superar las divisiones profundas» (Jellinek, 2004, p. 314), propias de la premodernidad europea, entre, por un lado, el rey y el pueblo, y, por el otro, el poder temporal y el poder espiritual. En una etapa marcada por la profunda inestabilidad institucional del poder, la voz italiana Stato $^{3}$ emergió en el siglo XV para designar de manera general a las diversas formas de poder político que poblaban entonces el panorama europeo. Con ella fue posible integrar en un solo término la dimensión poblacional, a la que se referían los vocablos antiguos griego (polis) y romano (civitas), y la dimensión territorial, dominante en la época medieval (Jellinek, 2004, p. 153; Bobbio, 2006, p. 87).

Desde la perspectiva weberiana, el Estado moderno asegura su superior eficacia y legitimidad por el recurso a dos técnicas racionales: la burocracia profesional y el derecho positivo. La superioridad del Estado frente a otros modos de dominación político-territorial deriva de su organización técnico-racional, pero su carácter distintivo

${ }^{3}$ Posterior y lentamente transmitida a los idiomas francés y alemán durante los siglos XVI y XVII (Jellinek, 2004: 156). 
no se asocia a su dimensión administrativa -finalmente, los partidos, las empresas y las iglesias han atravesado el mismo proceso de burocratización- sino a su dimensión política. En ese sentido, el Estado aparece como «aquella comunidad humana que en el interior de un determinado territorio (...) reclama para sí (con éxito) el monopolio de la coacción física legítima» (Weber, 2004, p. 1056).

Si bien dominante, la perspectiva weberiana no logró crear una síntesis satisfactoria entre las dimensiones funcional e institucional del Estado, es decir, entre lo que el Estado hace y lo que parece (Mann, 2007, p. 57). Otras concepciones intentan precisamente recuperar el doble carácter de la dominación estatal, identificando al Estado, por un lado, como el principal mecanismo de articulación de las relaciones sociales y, por el otro, como un conjunto de instancias y dispositivos desagregados, que no suelen operar siempre -o casi nunca- de un modo coherente (O’Donnell, 1978; Oszlak y O’Donnell, 1995; Benz, 2010).

Este asunto remite a la cuestión de la inserción del Estado en el sistema social, una discusión que gira en torno al problema de las relaciones Estado-sociedad y al consecuente grado de autonomía que se le reconoce al poder estatal. Como precisa Bobbio (2006), la reflexión sobre el vínculo entre Estado y sociedad ha experimentado un viraje histórico. Mientras la filosofía política antigua, con su característica fusión entre las esferas social y política, asumía a la polis como el todo y a los grupos sociales como partes, el pensamiento moderno ha supuesto a la sociedad como el campo general de las relaciones societales y al Estado como el componente coactivo de dichas relaciones.

Frente a la tendencia, común a las teorías marxista, liberal y funcionalista, de reducir el Estado a una arena de lucha entre clases, grupos o estamentos sociales, carente por sí mismo de autonomía, Mann (2007) subraya la necesidad de diferenciar entre dos tipos de poder estatal. El denominado «poder despótico» se refiere a la capacidad de la élite estatal de emprender acciones compulsivas sin negociar institucionalmente con grupos organizados de la sociedad civil. Por el contrario, el «poder infraestructural» remite a «la capacidad del Estado para penetrar realmente la sociedad civil y poner en ejecución logísticamente las decisiones políticas por todo el país» (Mann, 2007, p. 58).

Este poder infraestructural deriva del carácter peculiar del Estado como instancia territorial central: la sociedad civil necesita funcionalmente la regulación territorial centralizada de algunas de sus actividades, por lo que se ve obligada a ceder recursos de poder a la élite estatal, recursos que no puede recuperar debido a su diferente base socio-espacial (ni territorializada ni centralizada) (Mann, 2007, p. 75). De este modo, el Estado se asegura autonomía y cierto margen de discrecionalidad en su toma de posición.

Una noción semejante proviene de la literatura sobre el desarrollo. Evans (1996) define la "autonomía enraizada» como la capacidad del Estado para combinar el aislamiento -asociado a la autonomía y coherencia propias de las burocracias weberianas- con el enraizamiento, manifestado en el establecimiento de vínculos externos que permiten a los decisores estatales evaluar, controlar y modelar las reacciones de los actores no-estatales frente a las políticas públicas (Evans, 1996, p. 557). Esta síntesis sería característica de los Estados desarrollistas, aquellos que, a partir de «la institucionalización duradera de un complejo conjunto de mecanismos políticos», han generado capacidades para impulsar y dirigir con éxito cambios estructurales (Evans, 1996, p. 530).

La autonomía y el enraizamiento son aspectos problemáticos de las relaciones institucionales entre el Estado y la sociedad. La definición de los contenidos y límites de estas relaciones constituye, precisamente, el punto neurálgico de las reformas estatales. Se trata de un asunto crítico en tanto conlleva replantear las reglas del juego social en términos funcionales, materiales y de poder, esto es, en los planos de la división social del trabajo, la distribución del excedente social y la correlación de fuerzas políticas (Oszlak, 1997, p. 7).

La revalorización de la cuestión socio-estatal, producida al calor del ciclo de crisis, reforma y consolidación abierto en la década de 1980, ha animado el ascenso de las perspectivas neoinstitucionalistas. Para Benz (2010, p. 137), el Estado, en tanto macro-institución, está definido por seis atributos o principios institucionales. Los tres primeros, el territorio, la nación y el poder, constituyen las normas diferenciales, que fijan los límites del Estado y le dan su forma externa, y los tres últimos, la constitución, la democracia y la burocracia, son normas estructurales en tanto determinan su forma interna (Benz, 2010, pp. 144-145).

Las transformaciones que han sacudido al Estado en las últimas tres décadas han impactado de manera diferenciada cada uno de estos atributos. Fenómenos 
como la desterritorialización de la política, el deterioro de la inclusividad nacional, el desplazamiento de las tareas estatales, la pérdida de centralidad normativa del régimen constitucional, la emergencia de nuevas y contradictorias manifestaciones democráticas, y la aplicación de nuevas técnicas «gerenciales» o posburocráticas de administración, estarían dando forma a un cambio estructural de «diferenciación de la estatalidad» (Benz, 2010 , p. 455), que, sin embargo, «no supone la decadencia del Estado muchas veces pronosticada» (Benz, 2010, p. 468).

Estas transformaciones no derivan solo de presiones externas, ajenas al control estatal, sino que muchas de ellas han emergido del ejercicio de la autonomía del Estado, es decir, de la intención reformista deliberada. Bajo el influjo de combinaciones particulares de presiones externas e iniciativas internas, las llamadas «reformas» del Estado no han seguido un patrón único o universal, sino que se han configurado en un campo de disputas entre perspectivas normativas, programas estratégicos e instrumentos técnicos diversos y heterogéneos.

\section{La reforma del Estado: el Estado como problema}

La reforma del Estado se volvió un tema destacado de la agenda internacional durante la década de 1980. Sendas crisis afectaron, casi simultáneamente, a los tres modelos estatales dominantes tras el fin de la Segunda Guerra Mundial: el Estado de bienestar europeo, el Estado desarrollista latinoamericano y el Estado soviético del campo socialista (Lora, 2007).

$\mathrm{Si}$ bien las modificaciones deliberadas del aparato administrativo estatal no son un fenómeno nuevo (Oszlak, 1999), el posicionamiento más reciente de la «reforma del Estado» puede leerse como una manifestación de la crisis del reformismo moderno en tanto paradigma de transformación social. Para Sousa Santos (2004, p. 50), el paradigma reformista configuró «el proceso a través del cual el movimiento obrero y sus aliados encauzaron su resistencia contra la reducción de la vida social a la ley del valor, a la lógica de la acumulación y a las reglas del mercado». En este reformismo, cuya expresión política más acabada es el Estado de bienestar, «la sociedad es la entidad problemática, el objeto de la reforma, y el Estado, la solución del problema, el sujeto de la reforma» (Sousa Santos, 2004, p. 49).
Al entrar en decadencia, la fórmula reformista fue rápidamente invertida: el Estado pasó a ser el problema y, por tanto, el objeto privilegiado de las reformas. En la medida en que, tras el fin de la Segunda Guerra Mundial, al Estado le fue asignada la responsabilidad monopólica de conducir el cambio estructural para el desarrollo, las fallas de los proyectos social-industrial-desarrollistas fue achacada al fracaso estatal y, bajo el influjo del pensamiento neoutilitarista, se impuso la imagen opuesta del Estado como obstáculo determinante de los procesos de transformación (Evans, 1996).

La crisis del Estado fue analizada en una triple dimensión: fiscal, del modo de intervención y del tipo de administración (Bresser Pereira, 1998). Bajo este diagnóstico, se identificaron dos grandes ámbitos de intervención. Por un lado, la reforma del Estado fue definida en términos de uun cambio en las relaciones entre diferentes actores y agentes económicos, políticos y administrativos» (Fleury, 2000, p. 4). Su núcleo residiría en «la redefinición de las fronteras entre el dominio de lo público y lo privado», afectando "la extensión y la naturaleza de la intervención del Estado en los asuntos sociales» (Oszlak, 1993, p. 7). En cambio, la reforma administrativa se concretaría en «intentos deliberados de mejoramiento de uno o más aspectos de la gestión pública» (Oszlak, 1993, p. 7), particularmente los recursos humanos, los procesos, las tecnologías o el presupuesto. Mientras la reforma estatal apuntaría a la dimensión externa, la reforma de la administración pública sería necesariamente intraestatal.

La llamada «primera generación» de reformas, dominante en la década de los ochenta y el primer lustro de los noventa, estuvo imbuida por el pensamiento neorracionalista y la aspiración al Estado mínimo. Su supuesto de partida fue el del Estado «irreformable»; debido a su carácter esencialmente ineficaz y predatorio, su propensión inevitable a la captación de rentas, la única estrategia viable sería su reducción (Sousa Santos, 2004, p. 56). Bajo un modelo mercantil unidimensional, estas reformas económicas operaron en tres dimensiones: la transformación del papel del Estado, por medio de medidas simultáneas de privatización, desmonopolización, desregulación y descentralización; el achicamiento consecuente del aparato institucional; y la reducción concomitante de la planta de personal (Oszlak, 1993; Guimarães, 1997).

A pesar de su eficacia en el control de la inflación y el 
saneamiento de las finanzas públicas, rápidamente resultaron evidentes las limitaciones $y$ efectos contraproducentes de esta terapia de choque (Naím, 1994; Banco Mundial, 1997; Oszlak, 1999). En particular, el fortalecimiento institucional irrumpió como un postulado central (hasta entonces obviado) de los enfoques neoinstitucionalistas, dominantes en la «segunda generación de reformas». Aun así, el reconocimiento de las variables institucionales no dio pie a consensos normativos, estratégicos u operativos.

Por un lado, desde una postura neoinstitucionalista de la elección racional, se abogó por una «reinvención» empresarial del Estado en función de alinear los incentivos a los que se ven expuestos tanto sus operadores internos (políticos, directivos, rangos burocráticos medios e inferiores) como sus «grupos de interés» (contribuyentes, ciudadanos, usuarios). El énfasis estuvo colocado en el fortalecimiento de las capacidades estatales para «asegurar que los mercados prosperen», lo que implicaría dotar al Estado de un rol catalizador, promotor y orientador de las interacciones entre los agentes mercantiles (Naím, 1994; Banco Mundial, 1997). A nivel administrativo, este programa se materializó en la agenda neogerencialista de la Nueva Gestión Pública, enfocada en abrir las agencias públicas a la competencia e introducir técnicas y métodos propios del management privado.

Por el otro lado, desde una postura más sociológica, se articuló una apuesta por una «reinvención» democrática, orientada a reforzar las interdependencias solidarias entre el Estado y la sociedad civil (Sousa Santos, 2004). El objetivo sería romper el monopolio del poder a través de mecanismos de participación ciudadana, plural, igualitaria y deliberativa (Fleury, 2000, p. 14). Bajo nociones como «esfera pública no estatal» (Bresser Pereira y Cunill, 1998) y «matriz sociopolítica» (Garretón y Espinoza, 1993) se abogó por restituir al Estado sus capacidades directivas como agente de unidad, integración y redistribución, bajo una dirección y gestión pública participativa, transparente y responsable.

El dispositivo más conocido de esta concepción ha sido el presupuesto participativo, diseñado como mecanismo de democratización del aparato estatal. Sin embargo, más allá de acciones aisladas, introducidas en las periferias de la institucionalidad pública, estas nociones no han logrado articularse en un modelo integral de reforma del Estado (Sousa Santos, 2004). En ese sentido, vale preguntar ¿puede el gobierno abierto ser el paradigma articulador de estas ideas reformistas?; ¿pueden convertirse estos planteamientos en una «tercera», alternativa, agenda de reforma estatal?

\section{El gobierno abierto: una vieja idea (recientemente) redescubierta}

El gobierno abierto es un concepto polémico y debatido (Yu y Robinson, 2012; Peschard, 2013). Las diferencias sobre sus contenidos y límites se derivan de una multiplicidad de factores. En primer lugar, su uso ha proliferado muy recientemente, sin que haya transcurrido tiempo suficiente para consolidar sus alcances y sentidos. En segundo lugar, en torno a la noción se ha suscitado un amplio debate que ha concitado el interés de disciplinas académicas e instancias institucionales guiadas por lógicas divergentes. En tercer lugar, este debate no solo ha reunido intereses disímiles, sino que ha estado cruzado por la combinación -muchas veces confusade perspectivas normativo-prescriptivas y analíticodescriptivas. Finalmente, y consecuencia de todo lo anterior, el concepto se ha superpuesto, solapándose $\mathrm{y}$ entrando en tensión, con otras nociones mejor establecidas en la acción e investigación sobre régimen político, Estado, gobierno y gestión pública.

La idea seminal de gobierno abierto está asociada al pensamiento ilustrado del siglo XVIII, de raíz democrático-liberal. En efecto, la democracia se considera una condición necesaria del gobierno abierto (Manchado, 2010, p. 108). La primera norma moderna que acudió a esta categoría fue aprobada en Suecia en el siglo XVIII con el fin de garantizar la libertad de prensa (Pomed Sánchez, 2017, p. 169). Un antecedente más cercano es el amplio debate suscitado a mediados del siglo XX en Estados Unidos con motivo de la discusión y aprobación de la Ley de Acceso a la Información Pública (Ramírez-Alujas, 2010, p. 112), una norma tipo que, desde entonces, ha sido aprobada en más de 100 países (Oszlak, 2012, p. 9).

A pesar de su relevancia histórica, estos procesos configuran antecedentes lejanos y parciales. En los hechos, el gobierno abierto se ha convertido en tema central de la agenda pública internacional a partir de dos eventos muy recientes: la aprobación por parte del presidente estadounidense, Barack Obama, en enero de 2009, de un memorando sobre transparencia y «gobierno abierto», al que sucedieron luego otros decretos ejecutivos (RamírezAlujas, 2013-2014); y la creación, en 2011, de la Alianza para el Gobierno Abierto (AGA) (Open Government 
Partnership) (Ramírez-Alujas y Dassen, 2016), iniciativa de ocho países que, a mayo de 2018 , reúne a 76 .

Por otro lado, el gobierno abierto se ha convertido en asunto de interés de disciplinas diversas como la ciencia política, la administración pública, la sociología y los estudios sobre tecnologías de la información y la comunicación (TIC). Oszlak (2017, p. 214) identifica tres grandes corrientes que convergen en torno al concepto. Desde la corriente politológico-administrativa, el gobierno abierto es abordado como un problema institucional, de reforma del Estado y fortalecimiento de la gestión pública. En la corriente sociológica la discusión se ha enfocado en los desafíos de la organización social, las demandas de reconocimiento de derechos -sobre todo de acceso a la información- y las condiciones de movilización de la participación ciudadana. Finalmente, la corriente tecnológica asocia el gobierno abierto a los procesos de innovación digital, los proyectos de software libre y las aplicaciones de datos abiertos.

En una perspectiva delimitada solo a la ciencia política, Villoria Mendieta (2012, p. 6) identifica la convergencia de cuatro proyectos que reivindican la noción de gobierno abierto. Estos marcos articulan distintas creencias sobre el rol del Estado y la sociedad y se organizan en torno a diferentes ideales de gobernanza: 1. El gobierno regulador, promotor del bienestar; 2. El gobierno transparente que rinde cuentas; 3 . El gobierno participativo y promotor del civismo; y 4. El gobierno eficiente, colaborador y productor de conocimiento. La equidad, la transparencia, la corresponsabilidad cívica y la cooperación figuran como valores ordenadores en cada una de estas entradas.

La producción reciente sobre gobierno abierto, sin embargo, no ha sido exclusivamente académica. La categoría ha sido apropiada por diversas agencias internacionales, instancias gubernamentales y organismos independientes, guiando las políticas y estrategias reformistas en contextos muy diversos. Muchas de estas iniciativas no han derivado de concepciones explícitas o sistemáticas y han tendido a posicionar visiones normativas, las cuales, si bien han sido útiles para legitimar las acciones gubernamentales, han sesgado la discusión. El hecho de que la noción reemergiera en la discusión pública a partir de un memorando del presidente de los Estados Unidos es, sin duda, revelador. En ese sentido, se acumulan los cuestionamientos a esta «versión oficial» del gobierno abierto, tachada de superficial, imprecisa y reduccionista (Prieto-Martín y Ramírez-Alujas,
2014, p. 64).

Esta convergencia de inquietudes académicas e intereses políticos ha fracturado la discusión en dos grandes posturas (Cejudo, 2015). Desde una posición escéptica, se considera que el gobierno abierto no es más que una etiqueta de moda que tendrá una vida efímera y no producirá efectos relevantes en la vida política o el ejercicio gubernamental. En cambio, desde una posición entusiasta, se lo defiende como un principio novedoso capaz de penetrar las prácticas reales en función de mejorar la calidad de las políticas, incrementar la eficiencia de los servicios y ampliar la participación y la rendición de cuentas. La tensión abierta entre las distintas caracterizaciones -como etiqueta, principio o prácticaestaría expresándose en la formulación e implementación de las propias políticas.

Producto de estas imprecisiones, la primera tarea a la que se aboca la gran mayoría de trabajos sobre gobierno abierto, sean documentos oficiales o académicos, es la de proveer una definición del término. Para Cruz-Rubio (2015, p. 47), las distintas definiciones pueden agruparse en dos conjuntos. Un primer grupo de definiciones, de carácter sustantivo, destaca los principios y fundamentos del gobierno abierto, generalmente articulados en torno a la idea de un nuevo paradigma relacional o modo de gobernanza alternativo. El segundo grupo reúne definiciones instrumentales, en las que el gobierno abierto aparece como medio, estrategia o modo de acción gubernamental.

En correspondencia parcial con la fractura normativa previamente mencionada, la discusión ha estado cruzada por la tensión entre, por un lado, perspectivas más ambiciosas que conciben al gobierno abierto como un paradigma de reforma del Estado, expresión de un principio nuevo y alternativo de ordenación de las relaciones Estado-sociedad, y, por el otro, perspectivas más modestas que vinculan el gobierno abierto a la reforma de la administración pública a través de la incorporación de instrumentos, herramientas y técnicas facilitadas por los avances de las TIC.

Mientras el primer enfoque apunta al gobierno abierto como paradigma de organización estatal (fin), el segundo lo asume como modelo de organización administrativa (medio). Mientras el primero se articula en torno a un conjunto de principios democráticos que incluye la transparencia, la rendición de cuentas, la participación, 
el control democrático, el empoderamiento y la cooperación, el segundo se limita a una concepción restringida de la transparencia como disponibilidad de información pública, presentada idealmente en formato abierto, accesible, comprensible y reutilizable.

Mientras esta segunda concepción predominó en los significados asignados a la «apertura» como transparencia, dominantes en las normas y discursos oficiales hasta inicios del siglo XXI (Filgueiras, 2011), la primera ha emergido de la revitalización de la discusión sobre gobierno abierto producida en los años recientes. Este debate ha estado orientado por la necesidad de responder al doble desafío implicado por la crisis de legitimidad del sistema político-administrativo (Brugué, 2013) y la crisis paradigmática de las ciencias políticas y administrativas (Ramírez-Alujas, 2010). Más que al gobierno abierto a secas, estas concepciones podrían redirigirse, respectivamente, al Estado abierto y a la administración pública abierta, siendo esta segunda condición necesaria del primero.

El propio (Cruz-Rubio, 2015) intenta conciliar estas dos perspectivas al ofrecer una definición del gobierno abierto en la que reúne las dimensiones sustancial e instrumental. Para este autor, se trata de

Una filosofía político administrativa, un nuevo paradigma o modelo de interacción sociopolítica que -basado firmemente en los valores y principios de transparencia, de la democracia participativa y empoderamiento ciudadano, de la rendición de cuentas, el open data y del uso de avances tecnológicos, y en la conformación de gobiernos como plataformas que promueven la colaboración e interacción- se constituye como un modo y/o estrategia para el diseño, implementación, control y evaluación de políticas públicas y para procesos de modernización administrativa, y que ubica al ciudadano en el centro de atención y de prioridad, ofreciendo así una alternativa para la gestión de lo público. Como filosofía político administrativa, es pues diferenciable respecto de otras estrategias o filosofías político-administrativas existentes. (Cruz-Rubio, 2015, p. 51)

\section{El gobierno (Estado) abierto como paradigma de reforma del Estado: una «tercera generación» en ciernes}

El Estado moderno, en tanto estructura de dominación, es por concepto una entidad cerrada y opaca. Se caracteriza por la concentración de los medios materiales y administrativos y el secreto de sus actividades: la primera lo libera de la dependencia frente a agentes externos, el segundo lo protege de los controles exteriores. La burocracia apela a incrementar la superioridad de su conocimiento mediante el secreto. Como aclara el propio Weber $(2004$, p. 744) «el gobierno burocrático es, por su misma tendencia, un gobierno que excluye la publicidad. La burocracia oculta en la medida de lo posible su saber y su actividad frente a la crítica». La apertura, la transparencia y el control democrático son así, lógicamente, principios posburocráticos.

Del mismo modo, el régimen democrático moderno se funda en la separación entre gobernantes y gobernados, entre Estado y sociedad. El vínculo construido entre ambas esferas está limitado al mecanismo electoral; la ciudadanía solo interviene en el proceso político en condición de votante, quedando excluida de los procesos de transformación de la voluntad colectiva en normas jurídicas y programas administrativos, terreno exclusivo de los representantes políticos y los burócratas profesionales. La participación y colaboración, en ese sentido, solo se comprenden bajo una lógica posrepresentativa.

Como revelan sus valores, el gobierno abierto se orienta a transformar el Estado y replantear sus relaciones con la sociedad. Su ideal es la «reinvención» democrática del Estado. Al respecto, es posible concebirlo como una propuesta de reforma del Estado, una «tercera generación» de reformas, que emerge del «empaquetamiento» de los principios, programas e instrumentos de la apertura (transparencia y rendición de cuentas), la participación y la colaboración. Estos tres ejes, surgidos en distintos momentos, ordenados en distintos planos e impulsados por distintos movimientos, adquieren su sentido como vectores de la reforma estatal bajo el paraguas conceptual del gobierno abierto y, más precisamente, al menos en el mundo latino, del Estado abierto.

El alcance transformador de esta propuesta se constata en diversas definiciones planteadas en la literatura. Brugué (2013, p. 13) lo define como «una forma de gobernar» capaz de recuperar la legitimidad del sistema políticoadministrativo mediante la revitalización del valor de lo público y la reivindicación de los intereses colectivos. En una perspectiva igualmente ambiciosa, Calderón identifica el gobierno abierto como aquel que: 
Entabla una conversación con los ciudadanos con el fin de escuchar lo que ellos dicen y solicitan, que toma decisiones basadas en necesidades y teniendo en cuenta sus preferencias, que facilita la colaboración (...) y que comunica todo lo que decide y hace de forma abierta y transparente. (Calderón, 2012, p. 27)

En clave politológica, se subraya que el gobierno abierto es transversal a la democracia como modo de ordenación del acceso, ejercicio y control del poder. Se trata de «un elemento fundamental de cualquier gobierno en el cual haya acceso al poder en clave democrática, ejercicio de poder con calidad democrática, ciudadanos involucrados y un control del poder desde los ciudadanos» (Cejudo, 2015, p. 98). El gobierno abierto solo tiene sentido en un sistema democrático, operando como catalizador de la profundización de dichas lógicas (Manchado, 2010, p. 108). Desde el Consejo Latinoamericano de Administración para el Desarrollo (CLAD), se ha plasmado una definición claramente normativa, de acuerdo con la cual el gobierno abierto se materializa en:

El conjunto de mecanismos y estrategias que contribuye a la gobernanza pública y al buen gobierno, basado en los pilares de la transparencia, participación ciudadana, rendición de cuentas, colaboración e innovación, centrando e incluyendo a la ciudadanía en el proceso de toma de decisiones, así como en la formulación e implementación de políticas públicas, para fortalecer la democracia, la legitimidad de la acción pública y el bienestar colectivo. (CLAD, 2016, p. 5).

Dos autores latinoamericanos claves en la literatura sobre gobierno abierto, Álvaro Ramírez-Alujas y Oscar Oszlak, han desarrollado un amplio debate sobre las implicaciones del concepto en términos de reforma del Estado, su relación con otras nociones y enfoques, y su impacto en términos de políticas. Para Ramírez-Alujas (2012, p. 15; 2013-2014, p. 202), el gobierno abierto constituye una «filosofía sobre cómo gobernar en el siglo XXI»; una «doctrina política que sostiene que las actividades del gobierno y de la administración pública deben ser y estar abiertas a todos los niveles posibles para el escrutinio y supervisión eficaz de los ciudadanos» (Ramírez-Alujas, 2010, p. 110).

El gobierno abierto implicaría «un renovado paradigma de reforma del Estado y modernización de la administración pública a partir de una nueva forma de articular las iniciativas de transparencia, participación ciudadana y colaboración de diversos actores para la co-producción de valor público» (Ramírez-Alujas y Dassen, 2014, p. 1). Estas expresiones sustantivas -filosofía, doctrina y paradigma- dan cuenta del alcance y profundidad que se le ha dado al concepto en la región.

Bajo criterios similares, Oszlak (2012, p. 3) define el gobierno abierto como «una verdadera filosofía acerca de cómo gobernar y de cuál es el rol que juegan el gobierno y los ciudadanos en la gestión pública y en sus resultados». En términos concretos, entraña «una relación de doble vía entre ciudadanía y estado, posibilitada por la disponibilidad y aplicación de TIC (...) que facilitan múltiples interacciones entre actores sociales y estatales, y se traducen en vínculos más transparentes, participativos y colaborativos» (Oszlak, 2014, p. 3).

En la concepción de este autor, el gobierno abierto parte de tres supuestos implícitos muy ambiciosos. En primer lugar, se asume que la tecnología es capaz de producir una comunicación e interacción de doble vía gobierno-ciudadano. En segundo lugar, se concibe a los responsables del gobierno como dispuesto a abrir canales de diálogo para aprovechar la contribución social en las funciones de decisión, producción y control de la gestión pública. En tercer lugar, se supone que los ciudadanos tienen la capacidad e interés de aprovechar esa apertura para involucrarse en tanto co-decisores, co-productores y co-controladores de los asuntos públicos (Oszlak, 2012, p. 3).

La postura de Oszlak es en cierto sentido la más ambiciosa de las rastreadas en la literatura y la más coherente con la idea de gobierno abierto como reforma del Estado. A este respecto, despeja los vínculos entre gobierno abierto $\mathrm{y}$ otras nociones similares, muchas veces asimiladas, como gobierno electrónico (e-gov, en inglés) o datos abiertos (open data). Mientras el gobierno electrónico se limita a la dimensión instrumental-tecnológica, es decir, a la reforma administrativa, destinada a la mejora de la eficacia y eficiencia de los servicios públicos, los datos abiertos solo constituyen un momento inicial, asociado al principio de transparencia. En cambio, el gobierno abierto se inserta en las dinámicas de poder y los valores del orden social en función de producir un cambio cultural (no solo tecnológico), concitando iniciativas que transcienden -incluyendo- la apertura de datos y abarcan la rendición de cuentas, la participación y la colaboración (Oszlak, 2014).

Frente a los sucesivos fracasos de los proyectos estado- 
céntrico y mercado-céntrico, el gobierno abierto apuntaría a articular y ordenar una nueva matriz «socio-céntrica», en la cual el ciudadano se vuelve centro y protagonista de la gestión pública (Oszlak, 2012; Sánchez González, 2018).

La condición del gobierno abierto como proyecto de reforma estatal se revela no solo a nivel discursivo, sino que ha empezado a expresarse en las políticas y programas en ejecución. La AGA, instancia coordinadora de muchos esfuerzos en la materia, incorpora en su Declaración de Gobierno Abierto una perspectiva ambiciosa, orientada a la «prosperidad, bienestar y dignidad humana en nuestros propios países y en un mundo cada vez más interconectado» (AGA, s.f.). Esta ambición se revela en los cinco grandes desafíos a los cuales deben adscribirse los distintos compromisos establecidos por los países: 1 . Mejora de servicios públicos; 2 . Aumento de la integridad pública; 3. Manejo de recursos públicos con mayor eficacia y eficiencia; 4. Construcción de comunidades más seguras; y 5 . Aumento de la rendición de cuentas por parte de las empresas (Peschard, 2013, p. 29-30).

En un estudio sobre los primeros planes de acción emitidos por 26 países $^{4}$ miembros de la AGA, Kaufman (2014) contabiliza un total de 709 medidas comprometidas, las cuales organiza de manera inductiva en siete grandes áreas (y 32 sub-áreas): 1. Ampliar la información pública disponible para la ciudadanía; 2. Garantizar y mejorar el ejercicio del derecho a la información; 3 . Mejorar los servicios públicos y sus canales de entrega; 4 . Proteger los derechos de los usuarios y funcionarios; 5 . Incrementar la transparencia de la gestión pública; 6. Promover la participación ciudadana en la gestión estatal; y 7. Aumentar la capacidad institucional para una gestión abierta (Kaufman, 2014, p. 72).

Dentro de estos grandes enunciados se incluyen acciones y medidas ubicadas en distintos planos (aspectos culturales, normativos, institucionales, organizativos, administrativos y técnicos), sectores de política (administración interna, social, económica, seguridad, etc.) y niveles (ministerios, institutos, agencias autónomas, dependencias administrativas). Paradójicamente, la mayor proporción de compromisos $(29,5 \%)$ se vincula a la creación y desarrollo de capacidades institucionales internas, lo que refleja la consciencia de la necesidad de formatear y fortalecer el aparato estatal en función de la apertura, la participación y la colaboración.

Este estudio agregado esconde, obviamente, variaciones entre las realidades nacionales. Peschard (2013) revela diferencias importantes en el diseño y contenido de los planes de acción de los ocho países ${ }^{5}$ fundadores de la AGA. Por ejemplo, mientras en Brasil se desarrolló un proceso de consulta ampliamente participativo, coronado con la realización de la Conferencia Nacional sobre Transparencia y Control Social, lo que aportó como resultado un plan centrado en aspectos de transparencia, control ciudadano, fortalecimiento de la sociedad civil y combate de la corrupción. En Estados Unidos se desarrolló un proceso más tecnocrático que condujo a un diseño centrado en la innovación tecnológica (Peschard, 2013).

Un aspecto problemático que ha emergido en los procesos de formulación e implantación de las políticas de gobierno abierto ha girado en torno a la propia limitación conceptual y empírica de la noción. Sobre todo en el mundo latino, ha sido subrayada la necesidad, tanto política como académica, de sustituir la categoría acotada de gobierno abierto por la más amplia y estructural de Estado abierto (Oszlak, 2017; Sánchez González, 2018).

El open government adquirió sus contornos semánticos en el mundo anglosajón, en donde el término hace referencia al modo de gobernar o «gobernanza» como proceso de dirección de la sociedad más que al ámbito institucional delimitado por el Poder Ejecutivo (Oszlak, 2013). En ese sentido, Oszlak (2017) plantea la categoría de «Estado abierto» como un concepto más apropiado, útil para abarcar el ámbito institucional al que apunta el programa reformista y dar cuenta del carácter multinivel (normativo, estratégico y operativo) de los cambios sugeridos. En su concepción, con Estado abierto se hace referencia a:

La voluntad formalmente expresada por parte de gobiernos, parlamentos, cortes de justicia, organismos de control público u otras instituciones

\footnotetext{
${ }^{4}$ Argentina, Brasil, Canadá, Chile, Corea del Sur, Colombia, Costa Rica, El Salvador, España, Estados Unidos, Estonia, Filipinas, Finlandia, Gran Bretaña, Guatemala, Honduras, Indonesia, México, Noruega, Panamá, Paraguay, Perú, República Dominicana, Sudáfrica, Tanzania y Uruguay.

${ }^{5}$ EEUU, Brasil, México, Noruega, Reino Unido, Indonesia, Filipinas y Sudáfrica.
} 
estatales o paraestatales de promover la apertura de sus repositorios de datos, el acceso ciudadano a la información, la participación social en las distintas fases del ciclo de las políticas públicas, la rendición de cuentas y, en general, el control de la gestión pública por parte de la ciudadanía. (Oszlak, 2017, p. 212)

El éxito de la estrategia de gobierno abierto «está supeditado a que sus herramientas sean proyectadas a todos los órganos del Estado» (Montero, 2017, p. 80) y no se enclaustren en la rama ejecutiva, una dinámica de difusión que ya ha venido desplegándose en algunos países (Peschard, 2013). Cinco atributos distintivos caracterizarían al Estado abierto: 1. La implantación de la filosofía del gobierno abierto en toda la estructura estatal; 2. El refuerzo de los frenos, contrapesos y controles entre poderes del Estado; 3. El involucramiento de la ciudadanía en el diseño, producción, seguimiento, control y evaluación de las instituciones, políticas, programas y servicios públicos; 4 . La implantación de las innovaciones tecnológicas; y 5. El fortalecimiento de la cooperación intra, inter y extrainstitucional (Oszlak, 2017, p. 227). Los valores de la apertura, la participación y la cooperación fijan los límites normativos del concepto; los confines institucionales del Estado, sus límites estratégicos; el desarrollo tecnológico, sus límites operativos.

En efecto, el Estado abierto implica, además de la adopción de un enfoque articulado a nivel normativo, estratégico y operativo, la extensión de esta filosofía a toda la institucionalidad pública. Expresión del avance en este sentido es la proliferación de categorías institucionales open, de entre las que vale la pena destacar tres: el parlamento abierto (Opening Parliament.org, 2012), la justicia abierta (Jiménez, 2014) y el municipio abierto (Hernández-Bonivento, Gandur y Najles, 2014).

La apertura parlamentaria implica «un mayor compromiso con la transparencia y la participación ciudadana en el trabajo parlamentario» (Opening Parliament.org, 2012: i), en función de construir un nuevo patrón de representación (Sánchez González, 2018, p. 21). Este avance ha sido en alguna medida impulsado por el éxito del gobierno abierto y, al igual que este, se ha articulado en torno a los principios de la transparencia, la participación, la colaboración y los datos abiertos.

La justicia abierta implica «la extensión de la filosofía y los principios del Gobierno Abierto (especialmente Transparencia, Participación y Colaboración) aplicados al ámbito de la justicia donde la innovación $\mathrm{y}$, actualmente, las TIC son herramientas clave para estas iniciativas» (Jiménez, 2014, p. 19). El énfasis se ha colocado aquí en el acceso a la información judicial, el desarrollo de métodos alternativos de solución de conflictos y la extensión de la colaboración del sistema de justicia con la sociedad civil (Sánchez González, 2018, p. 22).

A pesar de estos avances, el desarrollo de las reformas en los tres poderes públicos clásicos ha marchado a tiempos y ritmos desiguales. Mientras que, hasta la fecha, la apertura en el Ejecutivo ha implicado el despliegue de las tres formas típicas de transparencia (activa, pasiva y colaborativa ${ }^{6}$ ), en el Legislativo las mejoras se han registrado en las modalidades activa y pasiva, y en el Judicial, solo limitadamente en la forma activa (Sánchez González, 2018, p. 25-26).

Finalmente, el municipio abierto se dirige a «aprovechar las ventajas comparativas de su proximidad con la ciudadanía para profundizar la interacción y mejorar la gestión de las administraciones locales» (HernándezBonivento, Gandur y Najles, 2014, p. 14). Esta orientación se inscribe en la tendencia a la consolidación de los gobiernos municipales como escenarios de interacción social. En la práctica, en la región latinoamericana han proliferado las aproximaciones innovadoras a la gestión local, basadas en «nuevos mecanismos de integración social y nuevas plataformas de colaboración entre sectores», entre los que se incluyen proyectos de datos abiertos, presupuestos participativos, aplicaciones para la interacción electrónica y centros de innovación y cocreación de políticas (Hernández-Bonivento, Gandur y Najles, 2014, p. 21).

\footnotetext{
${ }^{6}$ Cerrillo (2012) identifica tres tipos de transparencia:

- La transparencia activa consiste en la activación de mecanismos mediante los cuales la administración difunde determinada información a los ciudadanos.

- La transparencia pasiva implica, en cambio, el derecho de los ciudadanos de solicitar acceso a archivos y registros administrativos.

- La transparencia colaborativa, finalmente, demanda la reutilización de la información del sector público por parte de actores no-estatales.
} 


\section{Reflexiones finales}

En este trabajo se argumenta que el gobierno abierto o, más apropiadamente, en el contexto latinoamericano, el aún más reciente Estado abierto, constituyen un paradigma de reforma del Estado. Esta «tercera generación» de reformas se funda en una matriz socio-céntrica, conformada en torno a los principios de apertura, participación y colaboración. En su acepción ambiciosa, implica cambios en al menos tres planos de la acción colectiva socioestatal:

- A nivel macro (normativo), demanda un cambio cultural, referido al desplazamiento del culto al secreto $\mathrm{y}$ al control de la información y el conocimiento como recursos de poder por una lógica abierta, participativa, colaborativa, reticular e innovadora.

- A nivel meso (estratégico), implica una reforma normativa e institucional profunda, orientada por reglas de juego que incentiven comportamientos participativos y colaborativos.

- A nivel micro (operativo), se requiere una transformación de las estructuras organizativas y un rediseño de los procesos de acuerdo con métodos, técnicas e instrumentos «abiertos» e innovadores, conectados a los avances tecnológicos.

En su implementación práctica, como ocurrió con las dos generaciones previas de reforma estatal, el proceso necesariamente debe transitar por dos grandes etapas. La primera, la etapa «fácil», en la que los esfuerzos tienden a concentrarse en el pilar de la apertura, referida a la transparencia informativa y en alguna medida a la rendición de cuentas. En cambio, la segunda, la etapa "difícil», implica avanzar sobre la apertura participativa y colaborativa de los procesos, instancias y mecanismos decisionales en función de la co-decisión, co-implementación y co-evaluación de las políticas, programas y proyectos. Mientras la primera fase se limita a obligar al Estado a exponer la acción pública, sus resultados y razones, la segunda conlleva romper el propio monopolio estatal sobre dicha acción pública.

Los avances realizados hasta la fecha son limitados, desiguales y tímidos. Existe el riesgo siempre latente de que el proyecto se «fetichice» y se delimite a una etiqueta vacía, sin implicaciones programáticas (Cejudo, 2015), o a una técnica aislada, puramente restringida al uso de las tecnologías (Kaufman, 2014). Dos grandes brechas se abren inevitablemente entre la promesa y la realización: la primera, entre la utopía de un Estado totalmente transparente y abierto y el impacto real de las medidas comprometidas; la segunda, entre estos compromisos y su efectiva realización práctica (Oszlak, 2014, p. 51).

El balance no es, sin embargo, totalmente desalentador. $\mathrm{Si}$ bien el camino por recorrer es largo, las acciones en marcha apuntan en una dirección positiva. En algunos casos, el ingreso "por arriba» de la etiqueta, aun si como moda, está generando la proliferación de iniciativas y acciones concretas, capaces de incidir en las dinámicas socioestatales. En otros, la adopción "por abajo» de iniciativas específicas está produciendo un efecto de difusión hacia otros sectores, jurisdicciones y ámbitos, estimulando la progresiva configuración de un programa reformista.

Si bien, bajo la perspectiva ambiciosa aquí esbozada, una reforma del «Estado abierto» implica un despliegue horizontal y vertical en todo el aparato estatal, que impacta sobre los tres niveles de la acción pública, y estimula un avance integral sobre la apertura, la participación y la colaboración, no pueden menospreciarse los esfuerzos que, más o menos aisladamente, vienen desarrollándose en diversos reductos del sector público. La voluntad política, la presión social y la capacidad institucional deben alinearse para hacer avanzar esta agenda. Las limitaciones y fallas del viejo modelo son el principal estímulo en esta dirección.

\section{Referencias}

1. AGA. (s.f.). Alianza para el Gobierno Abierto. (Documento de presentación). Recuperado de: http://www.opengovpartnership.org/sites/default/ files/OGP_Booklet_Spanish_Digital.pdf

2. Banco Mundial. (1997). El Estado en un mundo en transformación. Informe sobre el Desarrollo Mundial 1997. Washington D.C.

3. Benz, A. (2010). El Estado moderno. Fundamentos de su análisis politológico. Madrid: Centro de Estudios Políticos y Constitucionales.

4. Bobbio, N. (2006). Estado, gobierno y sociedad: por una teoría general de la política. México D.F.: Fondo de Cultura Económica.

5. Bresser Pereira, L. C. (1998). La reforma del Estado de los años noventa. Lógica y mecanismos de control. Desarrollo Económico, 38(150), 517-550. 
doi: $10.2307 / 3467348$

6. Bresser Pereira, L. C. y Cunill, N. (1998). Entre el Estado y el mercado: lo público no estatal. En Bresser Pereira, L. C. y Cunill, N. (Coord.) Lo público no estatal en la reforma del Estado (pp. 25-58). Buenos Aires: CLAD y Paidós.

7. Brugué, Q. (2013). Regeneración democrática. Un marco para desarrollar el gobierno abierto. Deliberación, 3(22), 21-38.

8. Calderón, C. (2012). Por qué un Gobierno Abierto. En G. Concha y A. Naser (Eds.), El desafío hacia el gobierno abierto en la hora de la igualdad (pp. 2748). Santiago: CEPAL.

9. Cassese, S. (2003). La crisis del Estado. Buenos Aires: Abeledo Perrot.

10. Cejudo, G. 2015. Gobierno abierto en México: ¿etiqueta, principio o práctica? En Hofmann, A. (Ed.), Gobierno abierto. El valor social de la información pública (pp. 97-112). México D.F.: Instituto de Investigaciones Jurídicas. UNAM y ITAIP. Recuperado de: https://archivos.juridicas. unam.mx/www/bjv/libros/9/4016/8.pdf

11. CLAD. (2016). Carta Iberoamericana de Gobierno Abierto. Aprobada por la XVII Conferencia Iberoamericana de Ministras y Ministros de Administración Pública y Reforma del Estado, Bogotá. Recuperado de: https://www.sfp.gov.py/ sfp/archivos/documentos/CIGA_2016\%20final_ knawtdh9.pdf

12. Crozier, M., Huntington, S., y Watanuki, J. (1975). The Crisis of Democracy. Report on the Governability of Democracies to the Trilateral Commission. Nueva York: New York University Press.

13. Cruz-Rubio, C. (2015). ¿Qué es (y que no es) gobierno abierto? Una discusión conceptual. Eunomía. Revista en Cultura de la Legalidad, 8, 37-53. Recuperado de: https://e-revistas.uc3m.es/ index.php/EUNOM/article/view/2475/1359

14. Evans, P. (1996). El Estado como problema y como solución. Desarrollo Económico, 35(140), 529-562. doi: $10.2307 / 3467372$

15. Filgueiras, F. (2011). Além da transparência: accountability e política da publicidade. Lua Nova, (84), 65-94. doi: https://dx.doi.org/10.1590/S0102-

\section{4}

16. Fleury, S. (2000). Reforma del Estado (Documento elaborado para el Instituto Interamericano para el Desarrollo Social). Recuperado de: http://www. top.org.ar/ecgp/FullText/000000/FLEURY\%20 Sonia\%20-\%20Reforma\%20del\%20estado.pdf

17. Garretón, M. A. y Espinoza, M. (1993). ¿Reforma del estado o cambio en la matriz socio-política? El caso chileno. Perfiles Latinoamericanos, 1, 133170. Recuperado de: http://www.redalyc.org/ pdf/115/11500106.pdf

18. Guimarães, R. (1997). ¿El Leviatán en extinción? Notas sobre reforma del Estado en América Latina. Serie ensayos, documento No. 97/42. Instituto Latinoamericano y del Caribe de Planificación Económica y Social. CEPAL, Consejo Regional de Planificación. Santiago de Chile. Recuperado de: https://repositorio.cepal.org/bitstream/ handle/11362/7374/1/S978642_es.pdf

19. Hernández-Bonivento, J., Gandur, M. y Najles, J. (2014). Gobierno Municipal Abierto en América Latina: de la Proximidad Administrativa a la Acción Colaborativa. Washington D.C.: OEA.

20. Jellinek, G. (2004). Teoría general del Estado. México D.F.: Fondo de Cultura Económica.

21. Jiménez, C. (2014). Justicia abierta: transparencia y proximidad de la justicia dentro del actual contexto de Open Government. Barcelona: Centro de Estudios Jurídicos y Formación Especializada del Departamento de Justicia. Generalidad de Cataluña. Recuperado de: http://www.opengovpartnership. org/sites/default/files/justicia_oberta_recerca_ jimenez_spa.pdf

22. Kaufman, E. (2014). Los senderos del gobierno abierto: análisis cuantitativo y cualitativo de planes de acción". En Oszlak, O. y Kaufman, E. (Eds.), Teoría y práctica del gobierno abierto: lecciones de la experiencia internacional (pp. 59-206). Washington D.C.: IDRC y RedGealc-OEA

23. Lora, E. (2007). La reforma del Estado en América Latina: una revolución silenciosa. En Lora, E. (Ed), El estado de las reformas del Estado en América Latina (pp. 1-64). Washington D.C.: BID y Banco Mundial.

24. Manchado, A. (2010). Gobierno abierto. Una 
aproximación desde el Estado. En Calderón, C. y Lorenzo, S. (Coords.), Open Government: Gobierno abierto (pp. 107-132). Buenos Aires: Capital Intelectual.

25. Mann, M. (2007). El poder autónomo del Estado: sus orígenes, mecanismos y resultados. En Acuña, C. (Comp.), Lecturas sobre el Estado y las políticas públicas: retomando el debate de ayer para fortalecer el actual (pp. 55-78). Buenos Aires: Proyecto de Modernización del Estado.

26. Montero, G. (2017). Del gobierno abierto al Estado abierto: la mirada del Centro Latinoamericano de Administración para el Desarrollo. En Naser, A., Ramírez-Alujas, Á. y Rosales, D. (Eds.), Desde el gobierno abierto al Estado abierto en América Latina y el Caribe (pp. 53-82). Santiago: CEPAL.

27. Naím, M. (1994). Latin America: The Second Stage of Reform. Journal of Democracy, 5(4), 32-48. doi: 10.1353/jod.1994.0057

28. O’Donnell, G. (1978). Apuntes para una teoría del Estado. Revista Mexicana de Sociología, 40(4), 11571199. doi: $10.2307 / 3539655$

29. Opening Parliament.org. (2012). Declaración sobre la Transparencia Parlamentaria. Recuperado de: http://www.openingparliament.org/static/pdfs/ spanish.pdf

30. Oszlak, O. (1993). La reforma del Estado: el día después. En Bodemer, K. (Ed.), La reforma del Estado. Más allá de la privatización (pp. 45-83). Montevideo: FESUR.

31. (1997). Estado y sociedad: ¿nuevas reglas de juego? Reforma y Democracia, 9, 1-34. Recuperado de: http://unpan1.un.org/intradoc/groups/public/ documents/un-dpadm/unpan040068.pdf

32. (1999). De menor a mejor. El desafío de la segunda reforma del Estado. Nueva Sociedad, 160, 81-100. Recuperado de: http://nuso.org/media/ articles/downloads/2754_1.pdf

33. (2012). Gobierno abierto: promesas, supuestos, desafíos. Ponencia presentada en la VIII Conferencia Anual INPAE, San Juan de Puerto Rico.

34. (2013). Estado abierto: hacia un nuevo paradigma de gestión pública. Ponencia presentada en el XVIII Congreso Internacional del CLAD sobre
Reforma del Estado y de la Administración Pública, Montevideo.

35. (2014). Gobierno abierto: hacia un nuevo paradigma de gestión pública. En Oszlak, O. y Kaufman, E. (Eds.), Teoría y práctica del gobierno abierto: lecciones de la experiencia internacional (pp. 5-58). Washington D.C.: IDRC y RedGealc-OEA.

36. (2017). La noción de Estado abierto en el contexto de América Latina y el Caribe. En Naser, Á., Ramírez-Alujas, A., y Rosales, D. (Eds.), Desde el gobierno abierto al Estado abierto en América Latina y el Caribe (pp. 209-230). Santiago: CEPAL.

37. Oszlak, O. y O’Donnell, G. (1995). Estado y políticas estatales en América Latina: hacia una estrategia de investigación. Redes, 2(4), 99-128. Disponible en: http://www.redalyc.org/articulo. oa?id=90711285004

38. Peschard, J. (2013). "Del gobierno abierto a la transparencia proactiva: la experiencia del IFAI en 2011”. En Hofman, A., Ramírez-Alujas, Á., y Bojórquez Pereznieto, J. (Coords.), La promesa del gobierno abierto (pp. 27-50). México D.F.: ITAIP y IFAI.

39. Pomed Sánchez, L. A. (2017). Transparencia. Fundamentos: Cuadernos monográficos de teoría del estado, derecho público e historia constitucional, 9, 167-214. Recuperado de: https://www.unioviedo. es/constitucional/fundamentos/noveno/pdfs/07 luispomed.pdf

40. Prieto-Martín, P. y Ramírez-Alujas, A. (2014) Caracterizando la participación ciudadana en el marco del Gobierno Abierto. Reforma y Democracia, 58, 61-100. Disponible en: http://siare.clad.org/ fulltext/0075500.pdf

41. Ramírez-Alujas, Á. (2010). Innovación en la Gestión Pública y Open Government (gobierno abierto): una vieja nueva idea. Buen Gobierno, 9, 94133. Disponible en: http://revistabuengobierno.org/ home/wp-content/Documentos/BG9_6.pdf

42. (2012). Gobierno abierto es la respuesta: ¿cuál era la pregunta? Más Poder Local, 12, 14-22. Disponible en: https://dialnet.unirioja.es/servlet/ articulo? codigo $=4013852$

43. (2013-2014). Gobierno abierto. Eunomía. Revista en Cultura de la Legalidad, 5, 201-216. Recuperado de: https://e-revistas.uc3m.es/index.php/EUNOM/ 
article/view/2180/1116

44. Ramírez-Alujas, Á y Dassen, N. (2014). Vientos de cambio. El avance de las políticas de gobierno abierto en América Latina y el Caribe. Nota Técnica del BID No. 629. Recuperado de: https://publications.iadb. org/bitstream/handle/11319/6400/ICS\%20TN\%20 Vientos\%20de\%20cambio.pdf

45. (2016). Vientos de cambio II. Avances y desafíos de las politicas de gobierno abierto en América Latina y el Caribe. Nota Técnica del BID No. 998. Recuperado de: https://publications.iadb.org/ bitstream/handle/11319/7621/Vientos-de-cambioII-Avances-y-desafios-de-las-politicas-de-gobienoabierto-en-America-Latina-y-el-Caribe.pdf

46. Sánchez González, J. (2018). Transparentando los poderes públicos: Gobierno abierto, parlamento abierto y justicia abierta. Revista Venezolana de
Gerencia, 23(81), 11-30.

47. Sousa Santos, B. de. (2004). Reinventar la democracia. Reinventar el Estado. Quito: Abya-Yala y ILDIS-FES.

48. Villoria Mendieta, M. (2012). Transparencia y gobierno abierto: ¿qué gobierno quiere el gobierno abierto? Ponencia presentada en el XVII Congreso Internacional del CLAD sobre la Reforma del Estado y de la Administración Pública, Colombia, Cartagena de Indias.

49. Weber, M. (2004). Economía y Sociedad. Esbozo de sociología comprensiva. México D.F.: Fondo de cultura Económica.

50. Yu, H. y Robinson, D. G. (2012). The New Ambiguity of "Open Government". UCLA Law Review Discourse, 59(178), 178-208. Disponible en: https:www.uclalawreview.org/pdf/discourse/59-11 pdf 